\title{
Two new freshwater crayfishes (Decapoda: Parastacidae) from Whitsunday Island, The Coral Sea, Australia
}

\author{
Jason Coughran, Kathryn L. Dawkins, Rod Hobson and James M. Furse
}

\begin{abstract}
Two new species of the crayfish genus Cherax are described from Whitsunday Island in the Coral Sea, Cherax austini sp. n. and Cherax cid sp. n. These two island species are similar to the ' $C$. depressus' species group from the Queensland mainland, differing in spination of the chelipeds and the development of the rostral ridges and sternal keel. Remarkably, Cherax austini sp. n. displays faint development of a median ridge on the cephalon, a feature otherwise associated with the disjunct and phylogenetically distinct fauna from the extreme south-west of Western Australia. Genetic analyses supported the close relationship of these two new species to the ' $C$. depressus' group from the mainland, with a comparatively recent divergence event between these two island species.
\end{abstract}

\section{INTRODUCTION}

Cherax is one of the most diverse genera in the family Parastacidae, with 47 recognised species at the time of writing. In this paper we describe two additional species from Whitsunday Island, the largest island in the Whitsunday Group off the coast of Queensland, Australia (Fig. 1). Apart from a single specimen of Cherax depressus, Riek, collected by John Short in 1987 from Lindeman Island, $\sim 12 \mathrm{~km}$ south of Whitsunday Island (Davie 2011 personal communication), we are not aware of any other Cherax inhabiting islands this far north in the Coral Sea (i.e., $\sim 20^{\circ} \mathrm{S}$ ). The next closest island species is Cherax robustus, Riek which occurs on Fraser Island ( 700 $\mathrm{km}$ south, at $\sim 24^{\circ} 55^{\prime} \mathrm{S}$ ).

One of the species described here (Cherax austini sp. n.) was the subject of an earlier paper by two of the authors (JC and $\mathrm{RH}$ ), in which dried shell remains collected from a swamp on the eastern side of Whitsunday Island were discussed (Coughran \& Hobson submitted). A return expedition to the site allowed the collection of live specimens, enabling the formal description of the species presented herein. On that same expedition, an additional search of an un-named stream at the overnight anchorage/camp on the western side of the island (Cid Harbor) yielded specimens of a second species, which we also describe in this paper (Cherax cid sp. n.).

\section{METHODS}

\section{Collection of Specimens}

Crayfish were collected from Whitsunday Island on the $21^{\text {st }}$ and $23^{\text {rd }}$ of October 2010 by hand or with collapsible bait-traps, baited with dog biscuits, tinned sardines and tinned tuna. Specimens were preserved in $70 \%$ ethanol. The coordinates of collection sites were recorded using a Global Positioning System.

Extraction, amplification and sequencing of DNA

Extractions of DNA were obtained from specimens using a variation of the CTAB/phenol-chloroform extraction protocol (Doyle \& Doyle, 1987). The mitochondrial cytochrome oxidase subunit 1 (COI) gene fragment was amplified using the primers CRCOI-F (5'CWACMAAYCATAAAGAYATTGG-3') a $\mathrm{n} \mathrm{d}$ C R C O I - R ( $5^{\prime}$ GCRGANGTRAARTARGCTCG-3') (Cook et al. 2008). All PCR reactions were performed on a GeneAmp PCR System 2700 and contained the following: $2.0 \mu \mathrm{L}$ DNA extract, $0.4 \mu \mathrm{L}$ forward primer, $0.4 \mu \mathrm{L}$ 

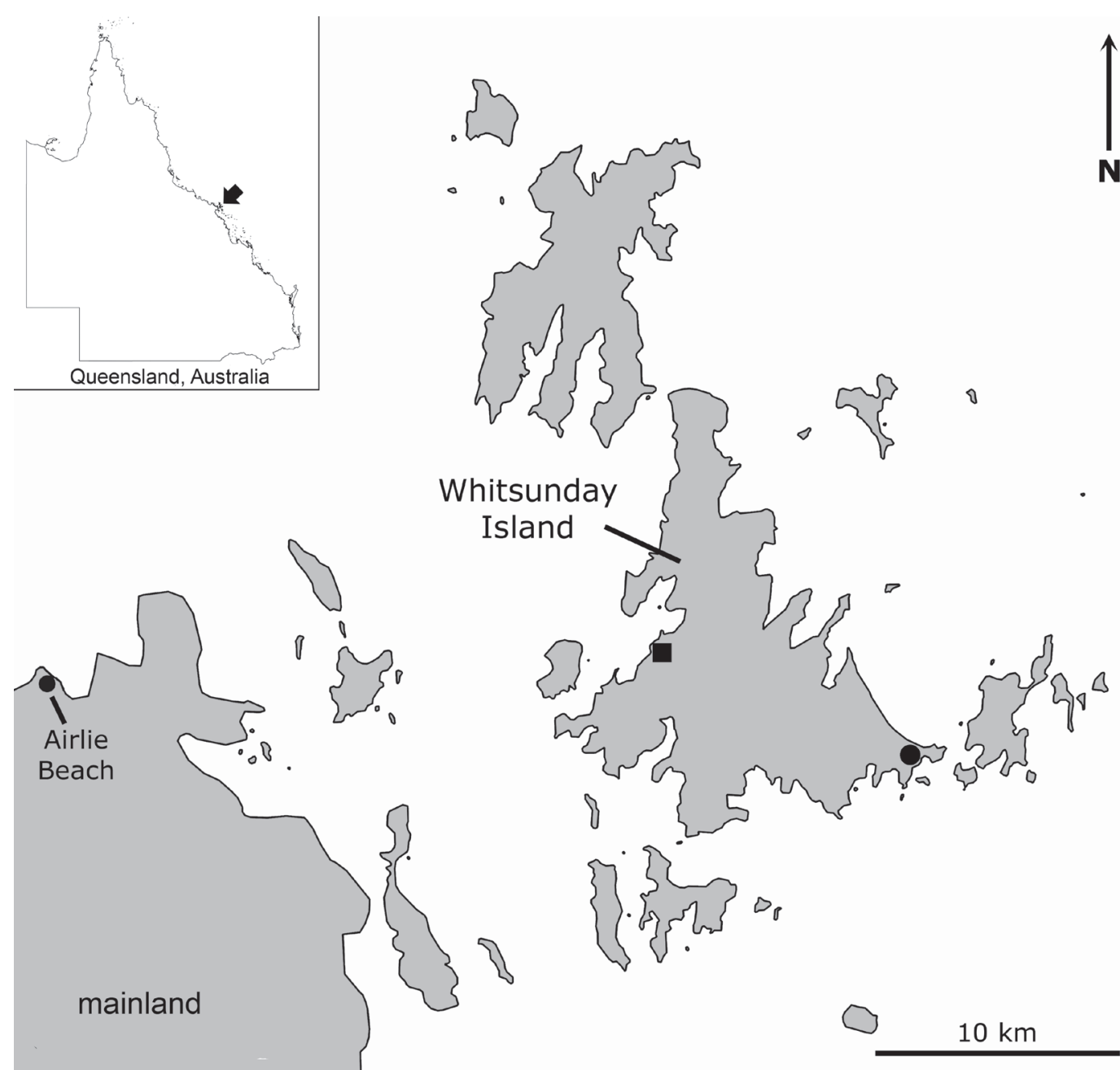

Fig. 1. Map of Whitsunday Island showing type localities of Cherax austini sp. n. (circle) and Cherax cid sp. n. (square). The entire island is within the Whitsunday Islands National Park, Queensland.

reverse primer, $0.32 \mu \mathrm{L}$ dNTP $(10 \mathrm{mM}), 0.7$ $\mu \mathrm{L} \mathrm{MgCl}_{2}(50 \mathrm{mM}), 1.25 \mu \mathrm{L}$ buffer $(10 \times)$, $0.35 \mu \mathrm{L}$ Astral Red Taq (1U) and $7.08 \mu \mathrm{L}$ $\mathrm{ddH}_{2} \mathrm{O}$. The amplification program consisted of the following conditions: $94^{\circ} \mathrm{C}$ for $5 \mathrm{~min}$; 40 cycles of: $30 \mathrm{sec}$ at $94^{\circ} \mathrm{C}, 1 \mathrm{~min}$ at $55^{\circ} \mathrm{C}$, $30 \mathrm{sec}$ at $72^{\circ} \mathrm{C}$; then $7 \mathrm{~min}$ at $72^{\circ} \mathrm{C}$, with the reaction stored at $4^{\circ} \mathrm{C}$ until further analysis. The DNA was then purified using EXO SAP (Fermentas) on successfully amplified samples. Purification reactions contained 0.25 $\mu \mathrm{L}$ Exonuclease I, 1.0 $\mu \mathrm{L}$ Shrimp Alkaline Phosphate and 5.0 $\mu \mathrm{L}$ amplified PCR product, with the solution then incubated at $37^{\circ} \mathrm{C}$ for $35 \mathrm{~min}$, heated at $80^{\circ} \mathrm{C}$ for $20 \mathrm{~min}$, held at $15^{\circ} \mathrm{C}$, then stored at $4^{\circ} \mathrm{C}$ until further analysis. Further amplification reactions contained: $1.0 \mu \mathrm{L}$ purified PCR product, $5.5 \mu \mathrm{L} \mathrm{ddH_{2 }} \mathrm{O}, 5.0 \mu \mathrm{L}$ Terminator Mix, $2.0 \mu \mathrm{L} 5 \times$ Terminator Mix Buffer and 1.0 $\mu \mathrm{L}$ of the forward primer (CRCOI-F), and PCR reactions consisted of the following conditions: initial hold of $96^{\circ} \mathrm{C}$ for $1 \mathrm{~min}$; 30 cycles of: $96^{\circ} \mathrm{C}$ for $10 \mathrm{sec}, 50^{\circ} \mathrm{C}$ for 5 sec, $60^{\circ} \mathrm{C}$ for $4 \mathrm{~min}$; then a final hold at $4^{\circ} \mathrm{C}$. Samples were cleaned and then sequenced on an Applied Biosystems 3130 automated sequencer. 


\section{Phylogenetic analysis}

All available Cherax sequences matching the COI gene fragment amplified from the 'unknown' specimens in this study were obtained from GenBank. From these, representative sequences from 13 different Cherax species (24 sequences from GenBank (Appendix 1) with an additional unpublished sequence of $C$. depressus from Bentley (2007)) were aligned with 6 'unknown' sequences (3 from each type locality) using Sequencher 4.1.2. (GeneCodes, 2000). To allow informative comparisons between species, all sequences were cut to a length of 379 base-pairs. From these final sequences, a maximum likelihood tree was inferred using the program RAxML v. 7.0.0 (Stamatakis, 2006) with 1000 bootstrap replicates. One sequence from the genus Gramastacus was also included in the analysis as an outgroup to root the phylogenetic tree. The mean net group sequence divergence estimates between species were calculated using MEGA5 (Tamura et al., 2011) and are presented as number of base substitutions.

\section{Morphological analysis}

Morphological examinations were performed with reference to earlier published taxonomic works on the genus (Austin, 1986; Sokol, 1988). All measurements were made to the nearest $0.01 \mathrm{~mm}$ using digital vernier calipers. Measurements of regenerate chelae were not included in morphometric ratios. The standard dimension in this study was Occipital-Carapace Length (OCL, Morgan, 1997), describing the oblique distance from the posterior radius of the eye socket to the centre dorsal posterior of the carapace.

Family Parastacidae Huxley, 1879

Genus Cherax Erichson, 1846

Cherax austini sp. n. Coughran \& Hobson

(Fig. 2)

Material Examined.-Queensland Museum QMW29124; Holotype; male; 38.90 mm OCL; unnamed Melaleuca swamp, Whitsunday Islands National Park, southeastern corner of Whitsunday Island, Queensland; $20^{\circ} 17^{\prime} 50^{\prime \prime S} 149^{\circ} 02^{\prime} 51^{\prime \prime}$; elevation $9 \mathrm{~m}$ above sea level (a.s.1.); Rod Hobson, Patrick Couper and Andrew Amey; $23^{\text {rd }}$ October 2010.

Paratypes; Queensland Museum QM-W29125 - QM-W29129; type locality; Rod Hobson, Patrick
Couper and Andrew Amey; 4 males, 1 female. The originally collected shell remains of the species (Coughran \& Hobson submitted), held in the Griffith University (School of Environment, Gold Coast) crayfish reference collection, were also examined but not measured or included in morphometric ratios.

Diagnosis.-Cephalon dorsally with a poorly developed median carina. Rostrum extending to near midlength of $3^{\text {rd }}$ antennal segment; carinae without spines and extending posteriorly to beyond anterior of postorbital ridges. Postorbital ridges moderately developed and with a small, blunt spine anteriorly; posteriorly, ridges broadening into pronounced bumps. Mesial margin of antennal scale uniformly convex. Uropodal basipodites with 1-3 tiny spines. Sternal keel sharp; deeply excavated between $1^{\text {st }}$ and $2^{\text {nd }}$ lateral processes; shallow excavation between $2^{\text {nd }}$ and $3^{\text {rd }}$ processes. Outer margin of chelae calcified; chelae glossy, punctuate and without setae apart from along cutting edges. Chelae elongate, with long, narrow and strongly curved fingers of more than half of the overall chela length; cutting teeth very fine. One large, angular mesial carpal spine. Mesial propodal spines extending to approximately two thirds of palm length; posteriorly, surface irregular without any well-defined spines; thereafter, 4-7 regular spines with an additional 1-3 tiny anterior spines.

Maximum Size: $38.90 \mathrm{~mm}$ OCL.

\section{Rostrum}

Rostrum extending apically to near midlength of third antennal segment. Posteriorly, carinae extending beyond anterior end of postorbital ridges. Carinae lacking spines, with anterior terminus rounded down to fuse with rostrum behind acumen without development of anterior spine. Acumen spine partially obscured by small clump of setae. OCL/Carapace Length: 0.82-0.84; Rostral Width/OCL: 0.13-0.15.

\section{Cephalothorax}

Poorly developed median ridge evident on dorsal surface of cephalon of most specimens, often terminating anteriorly in a distinct tubercle. Postorbital ridges moderately developed and terminating anteriorly in a poorly developed, blunt spine. 


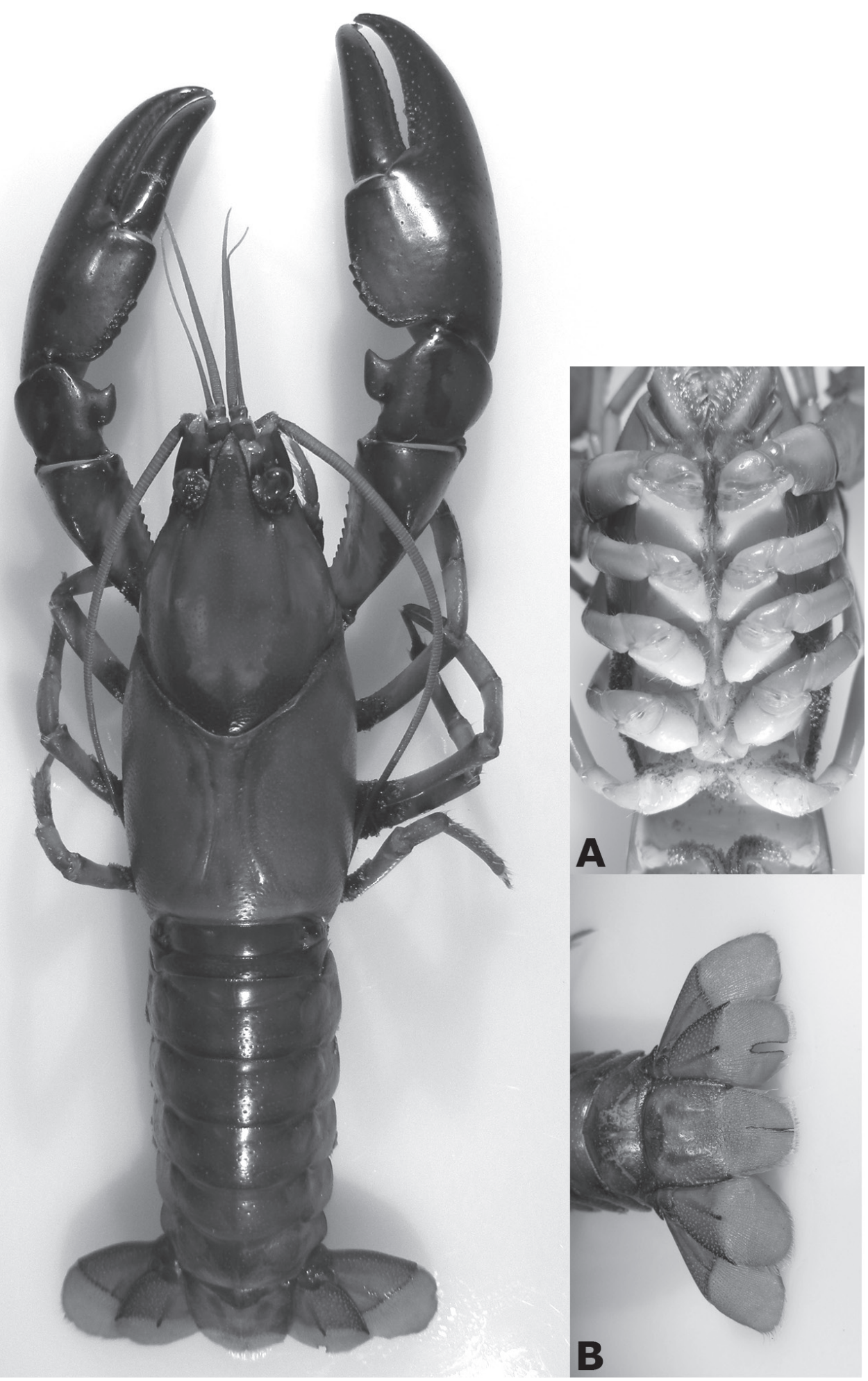

Fig. 2. Cherax austini sp. n. Holotype, QM-W29124, 38.90 mm OCL. Insets: A) sternal keel; B) tailfan. 
Posteriorly, postorbital ridges broadening into pronounced "bumps" (particularly well developed on holotype); distance between postorbital spines 1.57 to 1.69 times rostral width. Antennal squame generally uniformly convex, tapering posteriorly on some specimens. Interantennal spine broad, with smooth to slightly scalloped margins. Areola fusing dorsally with branchiocardiac groove. Narrow point at $0.39-0.45$ of areola length (from anterior end of areola). Cephalothorax with 4 to 5 small, blunt lateral cervical spines per side. Areola Length/OCL: 0.46-0.47; Areola Width/Areola Length: 0.13-0.18; Thorax Width/OCL: 0.54-0.59; Cephalon Width/Thorax Width: 0.82-0.89; Carapace Depth/OCL: 0.54-0.61.

\section{Abdomen and Tailfan}

Abdomen lacking spines. Lateral margin of telson with 2 sharp spines. Inner rami of uropods with central ridge ending posteriorly in a well defined spine, and with a well defined spine on lateral margin. Outer rami with a row of small, terminal spines along posterior margin of calcified section, and a central ridge terminating in a small spine of similar size to these; ridge also with a zone of tiny dorsal spines. Uropodal basipodites with 1-3 tiny spines. Abdomen Width/OCL: 0.51-0.56; OCL/Total Length: 0.37-0.39; Telson Length/OCL: 0.38-0.45.

\section{Chelae}

Chelipeds glossy and punctate. Dactylar and propodal fingers long, more than half the overall length of propodus. Both fingers with a strong ventromesial curve (when viewed ventromesially); fingertips prominently incurved mesially at almost $90^{\circ}$, produced to a sharp point. Cutting teeth of both fingers very fine, file-like. Merus. Dorsal surface of merus with 4-5 just discernible bumps. Carpus. Mesial surface of carpus with one large, angular spine, with a tiny second spine on the elbow of this large spine. Large male specimen lacking the tiny elbow spine, but with a distinctive oval punctuation in its position. One specimen with a second large mesial spine. Ventromesial surface of carpus with 1-2 anterior spines, and a row of 2-4 fine spines posteriorly. Propodus. Spines present on mesial propodal palm, extending to approximately $2 / 3$ of palm length from base; posteriorly, surface irregular without any well-defined spines; thereafter, 4-7 regular spines followed by 1-3 tiny spines (at apical end of spine row). Lateral margin of propodus calcified. Propodal Length (PropL)/ OCL: 0.98-1.18; Propodal Width/PropL: 0.33-0.38; Propodal Depth/PropL: 0.21-0.24. Dactylus. Dactylus lacking spines. Lateral margin of dactylus straight in dorso-lateral view with a slight outcurve in anterior third. Dactylar Length/PropL: 0.52-0.56; Dactylar Length/Palm Length: 1.27-1.52. Most specimens, including the holotype, have one slightly smaller, presumably regenerate, cheliped.

\section{Sternal keel}

Sternal keel sharp, deeply excavated between lateral processes to the first (LPr1) and second ( $\mathrm{LPr} 2)$ pereiopods, rising to a prominent peak at LPr 2. Keel moderately excavated between LPr 2 and LPr3, with a deep notch at LPr3. Keel prominently developed with an angular profile between LPr3 and LPr4, and a calcified triangular plate posterior to LPr4; ovoid sternal pores on LPr4 (absent on right hand side of holotype).

\section{Setation}

Setation of chelipeds absent, apart from sparse setae along cutting edges of fingers ventrally. Setation distinctly absent on merus, dorso-mesial margin and dorsal surface of propodus, and mesial surface of carpus (tiny amount of setae present on some small specimens).

\section{Punctation}

Cephalon with fine punctations of moderate density, extending posteriorly along areola. Thorax with fine and dense punctations interspersed with a broad zone of sparsely-distributed, larger punctations dorso-laterally. Chelipeds with sparsely distributed, fine punctations. Abdomen with sparse, fine punctations dorsally, and moderate to dense punctations laterally.

\section{Colouration}

Dorsally, dark brown or green-brown; some dried shell remains grey or blue. 


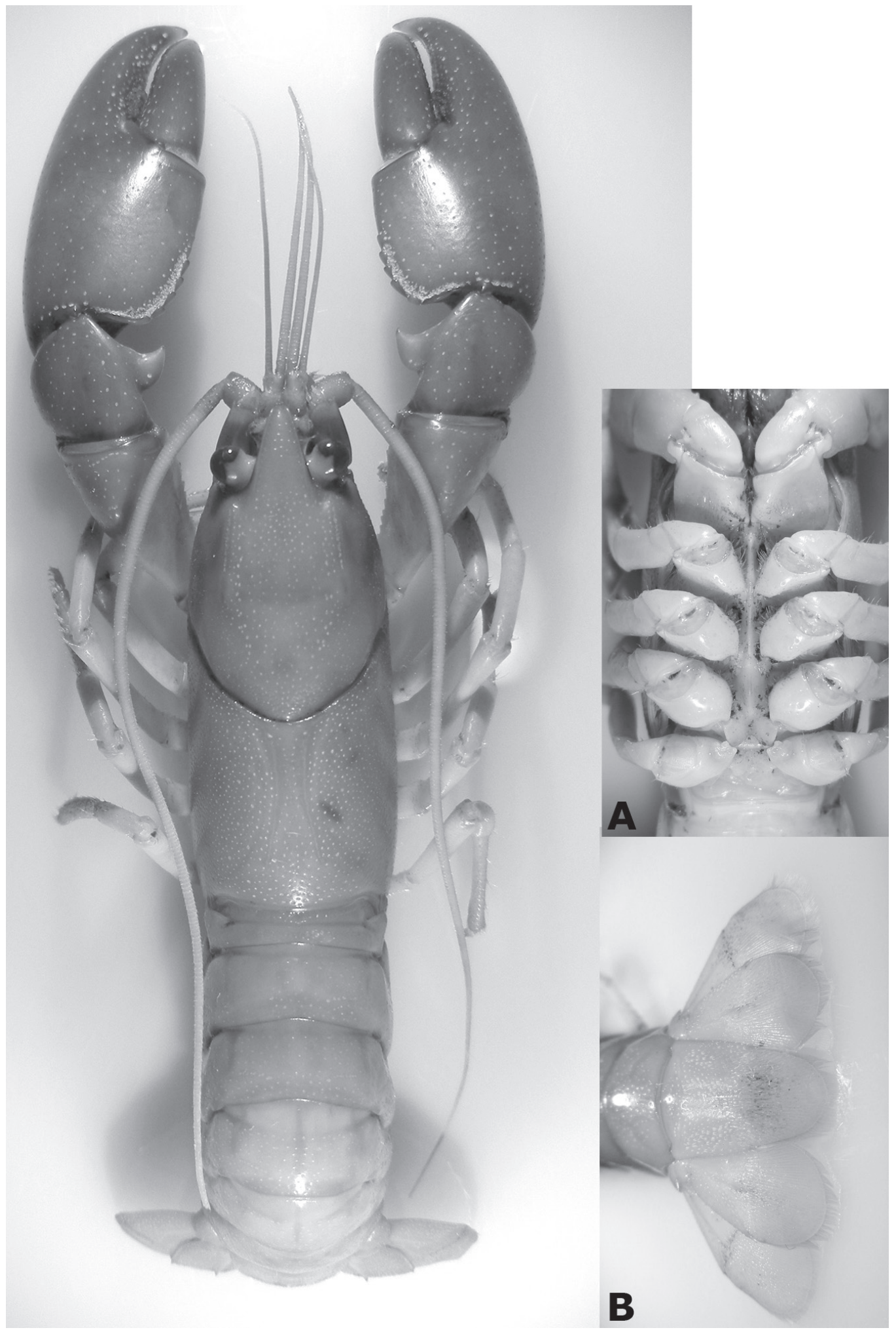

Fig. 3. Cherax cid sp. n. Holotype, QM-W29130, 27.74 mm OCL. Insets: A) sternal keel; B) tailfan 
Ventrally, light to medium grey to greenbrown; LPr3 and LPr4 and keel in between blue; merus of chelipeds grey; carpus and propodus dark blue; fingertips orange.

\section{Distribution}

The species is known only from the type locality.

\section{Biological Notes}

The species inhabits a single Melaleuca swamp. Water was heavily tannin-stained, with a deep and structurally complex substrate of organic detritus (a deep bed of leaves and fallen branches) and exposed Melaleuca roots. The swamp is bordered by a steep-sided bank, heavily impregnated with a mesh of Melaleuca roots and rootlets. No crayfish burrows were evident. Melaleuca swamp habitat is classified as Queensland Regional Ecosystem type 8.2.7, and is accorded "Endangered" Biodiversity Status throughout the State. The type locality is within one of only four protected areas of this habitat type in Queensland (DERM, 2011a).

All specimens have eggs of temnocephalan flatworms attached, and the large male specimen is heavily encrusted with temnocephalan eggs ventrally. This is a medium-sized species of Cherax. The only female specimen is $31.45 \mathrm{~mm}$ OCL and is mature, with soft, membranous gonopores with light marginal setation. This species was first detected on the island by the discovery of shell remains in midden formations around the shoreline of the swamp, likely from a predator such as Hydromys chrysogaster (the Eastern Water Rat) (Coughran \& Hobson, submitted).

\section{Etymology}

Named for Christopher M. Austin, whose research on the genus Cherax (e.g., Austin, 1986, 1996; Austin \& Knott, 1996) has contributed enormously to our current understanding of this large and culturally significant group of crayfish.

Family Parastacidae Huxley, 1879

Genus Cherax Erichson, 1846

Cherax cid sp. n. Dawkins and Furse (Fig. 3)
Material Examined.-Queensland Museum QMW29130; Holotype; male; 27.74 mm OCL; small unnamed stream flowing into Cid Harbour, Whitsunday Islands National Park, western side of Whitsunday Island, Queensland; $20^{\circ} 15^{\prime} 31^{\prime \prime S ~ 148 ~ 57 ' 04 " E ; ~}$ elevation $48 \mathrm{~m}$ a.s.1.; Rod Hobson; $21^{\text {st }}$ October 2010.

Paratypes; Queensland Museum QM-W29131 QM-W29134; type locality; Rod Hobson; 3 males, 1 female.

Diagnosis.-Dorsal surface of cephalon smooth and without indication of a median carina. Rostrum extending to near base of $3^{\text {rd }}$ antennal segment; carinae lacking spines and extending posteriorly to beyond anterior edge of postorbital ridges. Mesial margin of antennal squame uniformly convex. Uropodal basipodites with 2-3 tiny spines. Sternal keel deeply excavated between 1 st and $2^{\text {nd }}$ lateral processes, moderately excavated between $2^{\text {nd }}$ and $3^{\text {rd }}$ processes. Chelipeds dull, punctuate and with minimal setation; lateral margin of propodus calcified. Carpus with a single, large, angular spine; secondary mesial spines absent. 4-6 mesial propodal spines, extending to near midlength of propodal palm.

\section{Maximum Size: 27.74 mm OCL.}

\section{Rostrum}

Rostrum extending to, or just beyond, base of $3^{\text {rd }}$ antennal segment. Posteriorly, rostral carinae extending beyond anterior edge of postorbital ridges. Carinae lacking spines, without any development of a spine anteriorly; terminus rounded down to fuse with rostrum behind acumen. Acumen spine partially obscured by small clump of setae. OCL/Carapace Length: 0.83-0.86; Rostral Width/OCL: 0.14-0.17.

\section{Cephalothorax}

Dorsal surface of cephalon without development of a median carina; groovelike depression along the mesial edge of each post orbital ridge, with a well defined line of large punctations extending posteriorly towards cervical groove. Postorbital ridges moderately developed, each terminating anteriorly in a poorly developed, blunt spine; spines $6.38 \mathrm{~mm}$ apart (1.40 to 1.65 times rostral width). Posteriorly, postorbital ridges terminating with very poorly developed but broad bumps. Areola fusing dorsally with branchiocardiac groove. Narrow point at 
0.28-0.36 of areola length (from anterior end of areola). Cephalothorax with 2 to 4 tiny lateral cervical spines per side. Antennal squame uniformly convex. Interantennal spine broad, with smooth margins. Areola Length/OCL: 0.42-0.46; Areola Width/ Areola Length: 0.11-0.19; Thorax Width/ OCL: 0.49-0.54; Cephalon Width/Thorax Width: 0.90-0.95; Carapace Depth/OCL: $0.55-0.60$.

\section{Abdomen and Tailfan}

Abdomen lacking spines. Lateral margin of telson with 2 moderate to sharply developed spines. Inner rami of uropods with central ridge ending posteriorly in a well defined spine, and with a well defined spine on outer margin. Outer rami with a row of small, terminal spines along posterior margin of calcified section, and a poorly developed central ridge terminating in a small spine of similar size to these. Uropodal basipodites with 2-3 tiny spines. Abdomen Width/OCL: 0.48-0.53; OCL/Total Length: 0.37-0.38; Telson Length/OCL: 0.43-0.48.

\section{Chelae}

Chelipeds dull and punctate. Dactylar and propodal fingers long, more than half the overall length of propodus. Both fingers with a gentle ventromesial curve (when viewed ventromesially); fingertips gently incurved mesially, produced to a moderate point. Cutting teeth of both fingers small, with one notably larger tooth. Merus. Spination on dorsal surface of merus poorly developed, with 1-6 barely discernible spines. Carpus. Mesial margin of carpus with 1 large, angular spine; single punctuation at angle of mesial carpal spine. Secondary mesial spines absent. Ventromesial surface of carpus with 1 anterior spine and row of 2-3 tiny spines posteriorly. Propodus. Spines present on mesial propodal palm, extending to approximately $1 / 2$ of palm length from base, or slightly further. Typically 4-6 mesial spines (one specimen with 7 spines on one side). Outer margin of propodus calcified. Propodal Length (PropL)/OCL: 0.98-1.13; Propodal Width/PropL: 0.40-0.44; Propodal Depth/PropL: 0.25-0.27. Dactylus. Dactylus lacking spines. Lateral margin of dactylus with gradual convex curve. Dactylar Length/ PropL: 0.55-0.57; Dactylar Length/Palm Length: 1.38-1.60. All specimens have one slightly smaller, presumably regenerate, cheliped.

\section{Sternal Keel}

Sternal keel sharp, deeply excavated between LPr1 and LPr2, rising to a peak at LPr2. Keel moderately excavated between LPr2 and LPr3, with a minor notch at LPr3. Keel prominently developed and with convex profile between LPr3 and LPr4, with a calcified trapezoidal plate posterior to LPr4; pore-like depressions present on LPr4 of 22 mm OCL male specimen.

\section{Setation}

Minimal setation on chelipeds, generally requiring a hand lens to discern. Dorsally, very fine setation along immediate inside edge of mesial propodal spine ridge and along cutting edges of fingers. Mesially, sparse setae anterior to mesial spine of carpus. Ventrally, setation restricted to along cutting edges of fingers.

\section{Punctation}

Medium sized punctations of moderate density on cephalon, extending posteriorly along areola. Thorax with dense punctations laterally. Chelipeds with sparse and fine punctations. Abdomen dorsally with sparse, fine punctations; abdomen laterally with moderate to dense punctations and occasional large punctations.

\section{Colouration}

Dorsally, grey-brown. Chelipeds light grey, with faint mottling pattern; fingers blue with prominent orange tips. Ventrally, creamy pink-white; dactylar finger lilacblue; fingertips orange; cutting edges, anterio-mesial margin of merus and mesial half of carpus turquoise-blue.

\section{Distribution}

The species is known only from the type locality.

\section{Biological Notes}

The species was found inhabiting a small, clear and flowing stream with rocky substrate in a Notophyll vine forest. Specimens were 


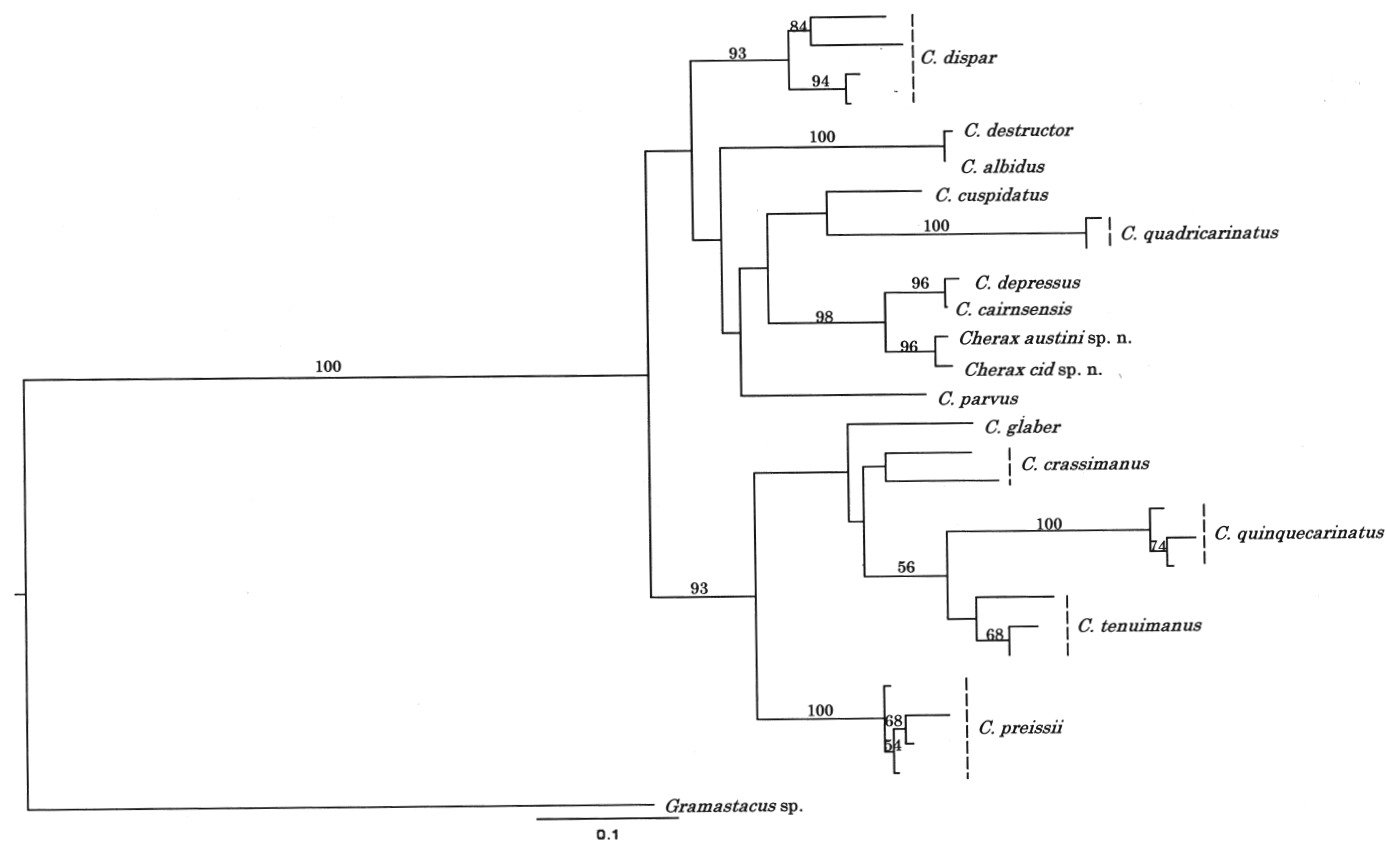

Fig. 4. Maximum likelihood bootstrap phylogram showing relationship between Cherax species (branch numbers shown are bootstrap support values $>50)$.

collected from around and under rocks, and no crayfish burrows were evident. Notophyll vine forest is classified as Queensland Regional Ecosystem type 8.12.18, and has a Biodiversity Status of "No concern at present" throughout the State. The type locality is within one of the 6 protected areas of this habitat type in Queensland (DERM $2011 \mathrm{~b})$. This is a relatively small species of Cherax. The only female specimen is $21.95 \mathrm{~mm}$ OCL and has incised gonopores, however they do not appear to be decalcified and setation is not evident around the margins of the gonopores.

\section{Etymology}

Named after Cid Harbour, where the collecting party moored their vessel in order to access the small creek where the type specimens were discovered.

\section{DISCUSSION}

\section{Molecular analyses}

For the specimens in this study, each type locality contained only a single but unique haplotype (with $96 \%$ bootstrap support between the two, Fig. 4). Although the divergence estimates in this study $(0.023 \pm 0.008$ Standard Error $(\mathrm{SE}))$ are comparatively low, they are more than double the divergence between the most closelyrelated species (i.e., C. depressus and Cherax cairnsensis, Riek; $0.011 \pm 0.006 \mathrm{SE}$ ) and are therefore consistent with the recognition of two new species (Table 1). It should also be noted that divergence estimates in this study far exceed divergence estimates between Cherax destructor Clark and Cherax albidus Clark (0.006 $\pm 0.004 \mathrm{SE})$ (Table 1) although treating $C$. destructor and $C$. albidus as distinct species is subject to ongoing debate. The relatively low divergence estimates between taxa in this study reflect a recent divergence event, as opposed to longer timeframes that are evident between other species.

Although the study of Munasinghe et al. (2004) examined different gene regions to this study (and therefore are not directly 
comparable), they presented a similar case for recognizing $C$. depressus and $C$. cairnsensis as distinct species. However, as Munasinghe et al. (2004) pointed out, C. depressus and C. cairnsensis are morphologically and genetically very similar, unlike the clear differences between the taxa in this study.

\section{Morphological analyses}

Morphologically, Cherax cid sp. n. is similar to crayfish in the 'depressus' complex of the coastal drainages on the Queensland mainland, and of these it is perhaps closest to $C$. cairnsensis. Cherax cid $\mathrm{sp}$. n. can be distinguished from this species in having fewer mesial propodal spines, shallower excavation of the sternal keel between LPr2 and LPr3, and rostral carinae that extend posteriorly beyond the anterior end of the postorbital ridges. In some respects, Cherax austini sp. n. is also similar to species in the 'depressus' complex, but can be readily distinguished by its unusual chelae and the dorsal ridge on the cephalon (Fig. 5). As has been discussed by Coughran \& Hobson (submitted), the latter character is of particular interest in the context of the genus, since it is otherwise only recorded on the Cherax fauna of far south-western Western Australia, a phylogenetically distinct subgroup in the genus (Austin, 1986).

In addition to the features described above, Cherax austini sp. n. and Cherax cid $\mathrm{sp}$. n. can be readily distinguished from each other by their broad morphological appearance. Cherax austini sp. n. is a medium size crayfish with a broad thorax and long, narrow and glossy chelipeds, with narrow fingers. In contrast, Cherax cid sp. n. is a relatively small crayfish, with a narrow thorax and stout, compact and dull chelipeds, with stout fingers. The median ridge on the dorsal surface of the cephalon further distinguishes Cherax austini sp. n. from all other eastern Australian Cherax.

These two new species are probably confined to Whitsunday Island, but their discovery should prompt further surveys on other Coral Sea islands. The aquatic habitats on Whitsunday Island are not extensive, and further exploratory surveys in ephemeral wetlands and minor drainages of other 


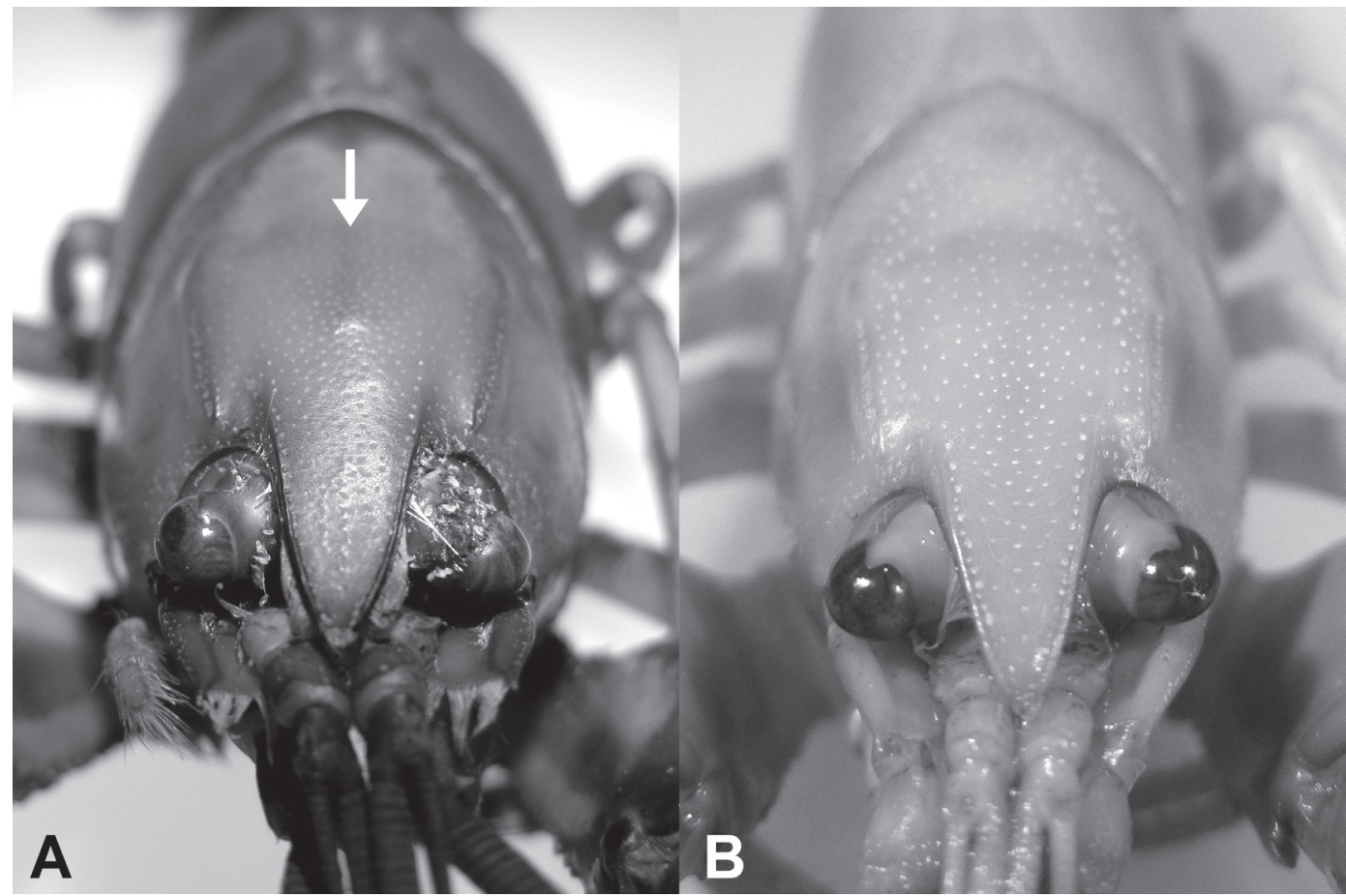

Fig. 5. The median ridge on the dorsal surface of the cephalon of Cherax austini sp. n. (A) is of particular interest. This feature is developed to varying degrees on the phylogenetically distinct and geographically disjunct Cherax fauna of south-western Western Australia, but otherwise absent in the eastern Australian fauna. Cherax cid sp. n. (B) displays the typical eastern state of a smooth cephalon with no indication of a median carina.

islands may yield additional discoveries. From a conservation perspective, the restriction of each of these species to a single, island locality is of note. Although no threats to either species have been identified at present, any management or development plans clearly need to take into account their potential vulnerability associated with their highly restricted distributions.

Acknowledgements.-The field expeditions to allow collection of specimens for this study were supported by The Queensland Department of Environment and Resource Management/Queensland Parks and Wildlife Service, Airlie Beach. Particular thanks are due to Department of Environment and Resource Management staff Simon Campbell, Damien Head, Stacy Ingram, Richard Johnson and Mark O'Brien, as well as Queensland Museum staff Andrew Amey and Patrick Couper for their assistance in the field during collection expeditions. Additional support for this research project was provided by the Environmental Futures Centre, Australian Rivers Institute and Griffith School of Environment (Griffith University, Gold Coast). We thank our two anonymous reviewers for their constructive comments on an earlier version of the manuscript.

\section{LITERATURE CITED}

Austin, C. M., 1986. Electrophoretic and morphological systematic studies of the genus Cherax (Decapoda: Parastacidae) in Australia. PhD Thesis. Department of Zoology, University of Western Australia. Perth, Western Australia.

Austin, C. M., 1996. Systematics of the freshwater crayfish genus Cherax Erichson (Decapoda: Parastacidae) in northern and eastern Australia: electrophoretic and morphological variation. Australian Journal of Zoology, 44: 259-296.

Austin, C. M., \& Knott, B., 1996. Systematics of 
the freshwater crayfish genus Cherax Erichson (Decapoda: Parastacidae) in south-western Australia: electrophoretic, morphological and habitat variation. Australian Journal of Zoology, 44: 223-258.

Bentley, A., 2007. A Phylogeographic structure of freshwater crayfish of the genus Cherax (Decapoda: Parastacidae) on the mainland and islands of southeast Queensland. Honours Thesis. Griffith School of Environment, Griffith University. Brisbane, Queensland, Australia.

Cook, B. D., Pringle, C. M., \& Hughes, J. M., 2008. Molecular evidence for sequential colonization and taxon cycling in freshwater decapod shrimps on a Caribbean island. Molecular Ecology, 17: 1066-1075.

Coughran, J., \& Hobson, R., Submitted. Crayfish shell remains from Whitsunday Island, Queensland. Submitted.

Davie, P. J. F., 2011. Senior Curator (Crustacea), Queensland Museum, Brisbane, Queensland, Australia.

DERM, 2011a. Regional ecosystem details for 8.2.7. Queensland Government, Department of Environment and Resource Management, Brisbane, Queensland, Australia.

DERM, 2011b. Regional ecosystem details for 8.12.18. Queensland Government, Department of Environment and Resource Management, Brisbane, Queensland, Australia.

Doyle, J. J., \& Doyle, J. L., 1987. A rapid DNA isolation procedure for small quantities of leaf tissue. Phytochemistry Bulletin, 19: 11-15.

GeneCodes, 2000. Sequencher (Version 4.1.2), Gene Codes Corporation, Ann Arbor, Michigan, USA.

Morgan, G. J., 1997. Freshwater crayfish of the genus Euastacus Clark (Decapoda: Parastacidae) from New South Wales, with a key to all species of the genus. Records of The Australian Museum Supplement, 23: 1-110.

Munasinghe, D., Burridge, C., \& Austin, C., 2004. The systematics of freshwater crayfish of the genus Cherax Erichson (Decapoda : Parastacidae) in eastern Australia re-examined using nucleotide sequences from 12S rRNA and
$16 \mathrm{~S}$ rRNA genes. Invertebrate Systematics, 18: 215-225.

Sokol, A., 1988. Morphological variation in relation to the taxonomy of the destructor group of the genus Cherax. Invertebrate Taxonomy, 2: 55-79.

Stamatakis, A., 2006. RAxML-VI-HPC: Maximum likelihood-based phylogenetic analyses with thousands of taxa and mixed models. Bioinformatics, 22: 2688-2690.

Tamura, K., Nei, M., \& Kumar, S., 2004. Prospects for inferring very large phylogenies by using the neighbor-joining method. Proceedings of the National Academy of Sciences (USA), 101: 11030-11035.

Tamura, K., Peterson, D., Peterson, N., Stecher, G., Nei, M., \& Kumar, S., 2011. MEGA5: Molecular Evolutionary Genetics Analysis using Maximum Likelihood, Evolutionary Distance, and Maximum Parsimony Methods. Molecular Biology and Evolution, 28: 2731-2739.

Addresses: (JC) Environmental Futures Centre, Griffith School of Environment, Gold Coast campus, Griffith University, Queensland 4222, and Outback Ecology, 1/73 Troy Terrace, Jolimont, Western Australia, 6014, Australia, (KLD) Australian Rivers Institute, Griffith School of Environment, Gold Coast campus, Griffith University, Queensland 4222, Australia, (RH) Queensland Parks and Wildlife Service, Department of Environment and Resource Management, Toowoomba, Queensland 4350, Australia, (JMF) Environmental Futures Centre, Griffith School of Environment, Gold Coast campus, Griffith University, Queensland 4222, Australia;

Email: (JC) jason.coughran@ outbackecology.com, (KLD) k.dawkins@ griffith.edu.au, (RH) rod.hobson@derm.qld. gov.au, (JMF) j.furse@griffith.edu.au 
Appendix 1. GenBank accession numbers for Cherax sequences used in this study. Note: The $C$. depressus sequence of Bentley (2007) is unpublished, and not included here

$\begin{array}{ll}\text { Species } & \text { GenBank Accession Number } \\ \text { C. dispar } & \text { GU902884.1 } \\ & \text { GU902904.1 } \\ & \text { GU902878.1 } \\ & \text { GU902879.1 } \\ \text { C. destructor } & \text { AY383557.2 } \\ \text { C. albidus } & \text { FJ965956.1 } \\ \text { C. cuspidatus } & \text { DQ006292.1 } \\ \text { C. quadricarinatus } & \text { DQ006294.1 } \\ & \text { DQ847531.1 } \\ \text { C. cairnsensis } & \text { EU921142.1 } \\ \text { C. parvus } & \text { DQ006293.1 } \\ \text { C. glaber } & \text { FJ965958.1 } \\ \text { C. crassimanus } & \text { EF118823.1 } \\ & \text { HM641127.1 } \\ \text { C. quinquecarinatus } & \text { HM641073.1 } \\ & \text { HM641105.1 } \\ \text { C. tenuimanus } & \text { HM641125.1 } \\ & \text { AF493631.1 } \\ & \text { AF510183.1 } \\ \text { C. preissii } & \text { AF510185.1 } \\ & \text { EF118808.1 } \\ & \text { EF118814.1 } \\ & \text { EF118816.1 } \\ & \text { EF118820.1 }\end{array}$


